\title{
Short communication: Genetic aspects of milk urea nitrogen and new indicators of nitrogen efficiency in dairy cows
}

\author{
T. Bobbo, ${ }^{1} \odot$ M. Penasa, ${ }^{1 *} \odot$ A. Rossoni, ${ }^{2} \odot$ and M. Cassandro ${ }^{1} \odot$ \\ ${ }^{1}$ Department of Agronomy, Food, Natural resources, Animals and Environment (DAFNAE), University of Padova, 35020 Legnaro (PD), Italy \\ ${ }^{2}$ Italian Brown Cattle Breeders Association (ANARB), 37012 Bussolengo (VR), Italy
}

\begin{abstract}
Milk urea nitrogen (MUN), a trait routinely measured in the national milk recording system, is a useful indicator of nitrogen utilization efficiency of dairy cows, and selection for MUN and MUN-derived traits could be a valid strategy to produce better animals with regard to efficiency of nitrogen utilization. Therefore, the aim of the present study was to explore the genetic aspects of MUN and new potential indicators of nitrogen efficiency, namely ratios of protein to MUN, casein to MUN, and whey protein to MUN, in the Italian Brown Swiss population. A total of 153,175 test-day records of 10,827 cows in 500 herds were used for genetic analysis. Variance components and heritability of the investigated traits were estimated using single-trait repeatability animal models, whereas genetic and phenotypic correlations between the traits were estimated through bivariate repeatability animal models, including fixed effects of herd-test-date, stage of lactation, parity, calving year, and calving season, and the random effects of additive genetic animal, cow permanent environment, and the residual. Heritability estimates for MUN ( 0.20 $\pm 0.01)$ and the 3 new indicators of nitrogen utilization efficiency $(0.15 \pm 0.01$ for protein-to-MUN and casein-to-MUN ratios, and $0.12 \pm 0.01$ for ratio of whey protein to MUN) suggested that additive genetic variation exists for these traits, and thus there is potential to select for greater organic nitrogen and lower inorganic nitrogen in milk. Genetic association between MUN and the 3 ratios was high $(-0.87 \pm 0.01)$ but not unity, suggesting that ratios could provide some further information beyond that provided by MUN with regard to efficiency of nitrogen utilization. Genetic trend of the investigated traits by year of birth of Brown Swiss sires showed how the selection applied in the last $30 \mathrm{yr}$ has led to an increase of both quantity and quality of milk, and a decrease of somatic cell score and MUN. The
\end{abstract}

Received February 28, 2020.

Accepted May 28, 2020.

*Corresponding author: mauro.penasa@unipd.it inclusion of MUN in breeding programs could speed up the process of increasing organic nitrogen such as protein, which is useful for cheese-making, and reducing inorganic nitrogen (MUN) in milk.

Key words: milk urea nitrogen, nitrogen efficiency indicator, genetic parameter, dairy cow

\section{Short Communication}

Urea, a small organic molecule synthesized in the liver from ammonia resulting from the degradation of proteins and other nitrogen compounds (Parker et al., 1995), is considered a useful indicator of efficiency of utilization of dietary nitrogen and of urinary nitrogen excretion (Jonker et al., 1998; Nousiainen et al., 2004). Once released into the blood, urea easily passes to milk (Broderick and Clayton, 1997), where it represents the primary component of nonprotein nitrogen. Although not included in milk quality payment systems, MUN of ruminants is an indicator of considerable interest to the farmer, as it provides information on the deficiency or excess of protein in the diet, and it is therefore adopted to monitor the nitrogen utilization efficiency of the animal (Roy et al., 2011). Indeed, MUN is used to evaluate the balance between carbohydrates and nitrogen sources in the rumen environment (Jonker et al.,1999; Aguilar et al., 2012). The balance in rumen digestion is fundamental not only to obtain optimal production from the qualitative and quantitative point of view, but also to guarantee the health status and the well-being of the animals.

Genetic selection for simultaneous increment of milk yield and improvement of milk quality and functional traits (e.g., health, longevity, fertility) is the main objective of many dairy cattle breeding programs (Miglior et al., 2017). Nevertheless, selection for MUN, which is often measured during routine monthly recording systems, would be a useful tool to improve nitrogen utilization efficiency of cows. Improving nitrogen efficiency of milk production is important to reduce environmental emissions of nitrous oxide and ammonia at farm level (Castillo et al., 2000). Currently, the possible 
use of MUN for breeding purposes in Italian Brown Swiss cattle is under investigation. However, information about genetic parameters for MUN and other possible indicators of nitrogen utilization efficiency, as well as genetic relationships with milk production traits, is still scarce. Therefore, the aim of the present study was to explore the genetic aspects of MUN and new potential indicators of nitrogen utilization efficiency, namely ratios of protein to MUN, casein to MUN, and whey protein to MUN, in the Italian Brown Swiss population. The inclusion of these ratios in breeding programs could help select to increase organic nitrogen such as protein, which is useful for cheese-making, and to reduce inorganic nitrogen (MUN) in milk.

Test-day milk records of Brown Swiss cows collected from 2014 to 2018 within the national routine milk recording system were provided by the Breeders Association of the Veneto Region (Padova, Italy). Data included milk yield $(\mathrm{kg} / \mathrm{d}$ ), composition traits (fat, protein, casein, and whey protein percentages), MUN $(\mathrm{mg} / \mathrm{dL})$, and SCC (cells/mL). Composition traits and MUN were determined using the MilkoScan FT6000 (Foss Analytics, Hillerød, Denmark) and SCC using the Fossomatic FC (Foss Analytics). Somatic cell count was log-transformed to SCS, according to Ali and Shook (1980). Three new potential indicators of efficiency of nitrogen utilization were calculated as the ratio of protein, casein, or whey protein to MUN. The original data set was edited to select cows between 5 and 500 DIM and with a minimum of 3 test-day records within lactation. Contemporary groups were defined as cows sampled in the same herd and day (herd-testdate, HTD), and HTD with fewer than 3 cows were removed. In addition, only cows with known sire and dam were retained. After editing, 1,049,919 test-day records of 72,613 cows in 3,335 herds were available for subsequent analysis. Due to computational issues, $15 \%$ of herds $(\mathrm{n}=500)$ were randomly selected for genetic analysis, leading to a subset of 153,175 test-day records of 10,827 cows. Pedigree information was provided by the Italian Brown Cattle Breeders Association (Verona, Italy), and included cows with phenotypic records and all their ancestors up to 6 generations back, for a total of 48,101 animals.

A preliminary investigation of the nongenetic factors affecting MUN and the 3 new candidate indicators of nitrogen utilization efficiency was conducted using SAS software version 9.4 (SAS Institute Inc., Cary, NC). The linear mixed model accounted for the fixed effects of stage of lactation (17 levels; the first being a class from 5 to 30 DIM, followed by 15 classes of $30 \mathrm{~d}$ each, and the last being a class $>480$ DIM), parity ( 5 levels: 1, 2, 3, 4, and $\geq 5$ ), calving year (5 levels: 2014 to 2018), and calving season (4 levels: winter compris- ing December, January, and February; spring, March, April, and May; summer, June, July, and August; and autumn, September, October, and November), and for the random effects of HTD (13,335 levels), cow, and the residual. Variance components and heritability of the investigated traits were estimated using single-trait repeatability animal models, and genetic and phenotypic correlations between the traits were estimated through bivariate repeatability animal models using the software VCE version 6.0 (Neumaier and Groeneveld, 1998). In all cases, models included the fixed effects of HTD, stage of lactation, parity, calving year, and calving season, and the random effects of additive genetic animal, cow permanent environment, and the residual. Variance components of the investigated traits were then implemented in the software PEST (Groeneveld et al., 1990) to obtain bulls' EBV, standardized to mean 100 and standard deviation 5 , and to assess the genetic trend by year of birth of sires with at least 5 daughters $(\mathrm{n}=1,267)$. Finally, we explored different scenarios to predict response to selection from a multitrait selection index.

Average milk yield and composition of Brown Swiss cows were consistent with the findings of Bobbo et al. (2016) for the same breed (Table 1). Milk urea nitrogen averaged $25.22 \mathrm{mg} / \mathrm{dL}$, and mean of the proteinto-MUN ratio was 0.17 , corresponding to the sum of the other 2 indicators of nitrogen utilization efficiency (ratios of casein to MUN and whey protein to MUN; Table 1).

Heritability of milk yield was $0.10 \pm 0.01$ (SE), and heritabilities of milk composition traits and SCS ranged from $0.09 \pm 0.01$ (SCS) to $0.37 \pm 0.02$ (casein percentage; Table 1). In the present study, dietary information was not available to be considered in examining genetic parameters of MUN and other nitrogen efficiency indicators, similar to previous studies (Wood et al., 2003; Miglior et al., 2007; Stoop et al., 2007). Therefore, a possible diet effect was likely accounted for by the HTD effect. Indicators of nitrogen utilization efficiency showed genetic variability, with coefficient of additive genetic variation from $7.97 \%$ (MUN) to $12.79 \%$ (caseinto-MUN ratio). Heritability of MUN $(0.20 \pm 0.01)$ was in agreement with the value $(0.17)$ estimated by Samoré et al. (2007) for the same breed, and within the range of 0.14 to 0.59 reported in the literature (Wood et al., 2003; Mitchell et al., 2005; Stoop et al., 2007); the wide variability of heritability estimates likely depends on breed, parity, and method used to determine MUN. Heritabilities of the 3 new indicators of nitrogen utilization efficiency were $0.15 \pm 0.01$ for protein-to-MUN and casein-to-MUN ratios, and $0.12 \pm 0.01$ for ratio of whey protein to MUN (Table 1). To the best of our knowledge, this is the first study to explore such ratios 
Table 1. Descriptive statistics, additive genetic variance $\left(\sigma_{\mathrm{a}}^{2}\right)$, permanent environmental variance $\left(\sigma_{\mathrm{pe}}^{2}\right)$, residual variance $\left(\sigma_{\mathrm{e}}^{2}\right)$, estimated heritability $\left(\mathrm{h}^{2}\right)$, and coefficient of additive genetic variation $\left(\mathrm{CV}_{\mathrm{a}}\right)$ of test-day milk yield, milk composition, SCS, and nitrogen efficiency indicators of Brown Swiss cows $(\mathrm{n}=153,175$ test-day records, 10,827 cows)

\begin{tabular}{|c|c|c|c|c|c|c|}
\hline Trait & Mean (SD) & $\sigma_{\mathrm{a}}^{2}$ & $\sigma_{\mathrm{pe}}^{2}$ & $\sigma_{\mathrm{e}}^{2}$ & $\mathrm{~h}^{2}(\mathrm{SE})$ & $\mathrm{CV}_{\mathrm{a}}, \%$ \\
\hline Fat & $4.13(0.73)$ & 0.0683 & 0.0312 & 0.2847 & $0.18(0.01)$ & 6.33 \\
\hline Protein & $3.70(0.42)$ & 0.0294 & 0.0117 & 0.0415 & $0.36(0.02)$ & 4.63 \\
\hline Casein & $2.88(0.33)$ & 0.0193 & 0.0081 & 0.0254 & $0.37(0.02)$ & 4.84 \\
\hline Whey protein & $0.82(0.12)$ & 0.0013 & 0.0007 & 0.0040 & $0.22(0.01)$ & 4.43 \\
\hline SCS & $2.86(1.86)$ & 0.2482 & 0.8524 & 1.6980 & $0.09(0.01)$ & 17.43 \\
\hline Protein:MUN & $0.17(0.08)$ & 0.0004 & 0.0002 & 0.0023 & $0.15(0.01)$ & 12.62 \\
\hline Casein:MUN & $0.13(0.06)$ & 0.0003 & 0.0001 & 0.0014 & $0.15(0.01)$ & 12.79 \\
\hline Whey protein:MUN & $0.04(0.02)$ & 0.0000 & 0.0000 & 0.0001 & $0.12(0.01)$ & 11.97 \\
\hline
\end{tabular}

as candidate indicators of efficiency of nitrogen utilization, and our results suggest that they show additive genetic variation potentially exploitable for breeding purposes.

Bivariate analysis suggested that selection to increase milk casein percentage is associated with an increase of fat percentage (genetic correlation of 0.64 ; Table 2), which indicates a simultaneous increment of components useful for cheese-making. In fact, although whey proteins are dispersed in the cheese whey, and nonprotein nitrogen has little nutritional value, caseins, together with fat, play a major role in cheese production. This result is in agreement with Samoré et al. (2007), who estimated a positive genetic correlation of 0.69 between fat and casein percentages in Brown Swiss cattle. In accordance with previous studies (Miglior et al., 2007; Samoré et al., 2007; Stoop et al., 2007), phenotypic correlations of MUN with milk yield, composition, and SCS were weak ( -0.08 to 0.07 ). Also, genetic relationships of MUN with milk yield and composition traits were weak (Table 2). In fact, MUN was weakly negatively correlated with milk yield $(-0.14)$, protein percentage $(-0.20)$, and casein percentage $(-0.22)$, and it was uncorrelated with fat percentage $(-0.03)$. These results partially agreed with findings of Samoré et al. (2007), who estimated a weak negative genetic correlation between MUN and milk yield $(-0.17)$, a null correlation with protein (0.03) and casein percentages (0.002), and a weak positive correlation with fat percentage (0.12). Miglior et al. (2007) reported a weak negative genetic correlation between MUN and milk yield $(-0.09)$, whereas moderate positive genetic correlations were estimated between MUN and fat percentage (0.42) and MUN and protein percentage (0.20) in Canadian Holsteins. Wood et al. (2003) reported genetic correlations of MUN with milk, protein, and fat yields that were generally weak ( -0.05 to 0.32$)$. Weak to moderate positive genetic associations between MUN and milk yield were observed by Stoop et al. (2007), Rzewuska and Strabel (2013), and Satoła et al. (2017). Mucha and Strandberg (2011) explored changes of correlation between MUN and milk yield during lactation and reported positive correlations at the beginning of lactation and negative at the end. In agreement with our results, weak to moderate negative genetic correlations between MUN and protein content were reported by Rzewuska and Strabel (2013) and Satoła et al. (2017). Moreover, Stoop et al. (2007), Rzewuska and Strabel (2013), and Satoła et al. (2017) reported null or weak genetic correlation between MUN and fat percentage. The new potential indicators of nitrogen utilization efficiency were weakly associated with milk yield (Table 2 ). Therefore, it is possible to improve ratios of protein or casein to MUN (i.e., to increase organic and decrease inorganic nitrogen), with only a trivial effect on milk yield. Overall, milk SCS, an indicator of udder health and milk quality, was weakly genetically associated with MUN (0.14) and with the 3 ratios of nitrogen utilization efficiency $(-0.10$ to -0.04 ; Table 2$)$. Therefore, selection to increase organic nitrogen at the expense of inorganic would allow a slow reduction of SCC. A strong positive genetic correlation (0.85) between MUN and SCS was reported by Stoop et al. (2007), although phenotypic correlation was almost null, similar to our study. Stoop and colleagues hypothesized the same genetic mechanism for both SCS and MUN, possibly as a result of variation of protein metabolism during mastitis. On the contrary, weak negative genetic correlations of -0.19 and -0.08 between MUN and SCS were reported by Miglior et al. (2007) and Samoré et al. (2007), respectively. Finally, genetic correlation between MUN and the 3 ratios was high $(-0.87)$ but not 
Table 2. Genetic ${ }^{1}$ (above diagonal) and phenotypic (below diagonal) correlations between test-day milk yield, composition, SCS, and nitrogen efficiency indicators

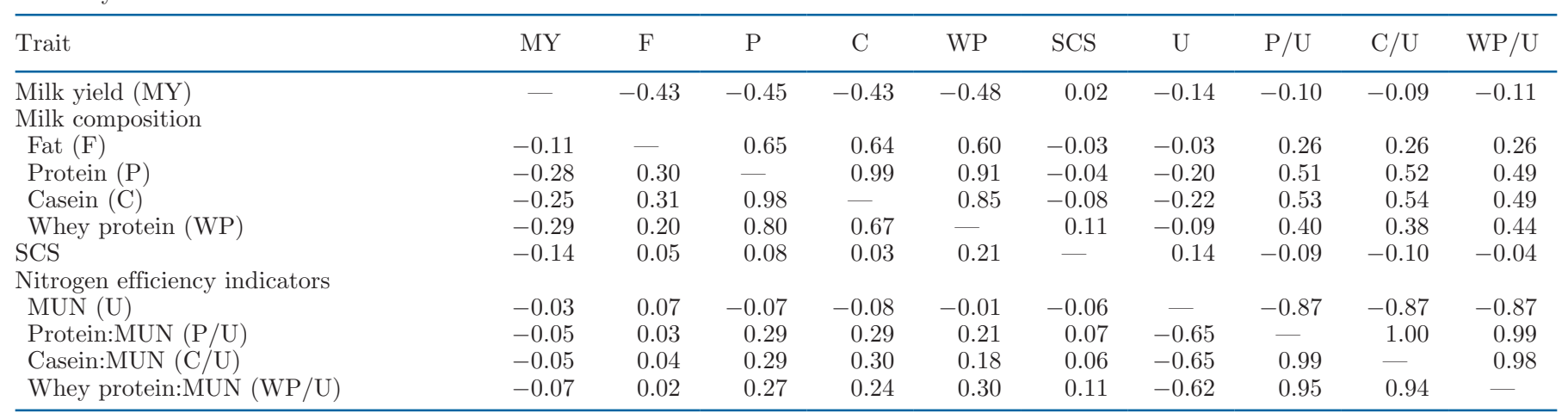

${ }^{1} \mathrm{SE}$ of genetic correlations ranged from 0.0001 to 0.09

unity, suggesting that ratios could provide some further information beyond that provided by MUN with regard to efficiency of nitrogen utilization.

Genetic trends of the investigated traits by year of birth of sires with at least 5 daughters $(\mathrm{n}=1,267)$ are depicted in Figure 1. The most remarkable result is that EBV were relatively stable until the mid-1990s, when their trends changed as a consequence of the introduction of the total economic index in Italian Brown Swiss cattle at the beginning of the 1990s; this resulted in an improvement of milk yield and composition and a decline of SCS and MUN (Figure 1).

Although the use of ratios in genetic selection has been considered problematic, the possible inclusion of one of the ratios (e.g., protein-to-MUN ratio) in the selection index of the Italian Brown Swiss population could be managed by knowing the effect of selection for the numerator (e.g., protein percentage) in the population. Hence we predicted different scenarios of response to selection using the Multiple Trait Selection Index, 20Trait Version, a spreadsheet for selection index calculations developed by Julius van der Werf (University of New England, Armidale, Australia; https://jvanderw .une.edu.au/software.htm), which provides response to selection of traits "per selection round," ignoring parental contribution, and with the only required parameters phenotypic standard deviation, heritability, repeatability, and correlation structure of the investigated traits. In addition, we set up several daughters with phenotypic information equal to 120 for the progeny test, as this is the minimum number of daughters required in Italy for a bull to be released as a proven bull.

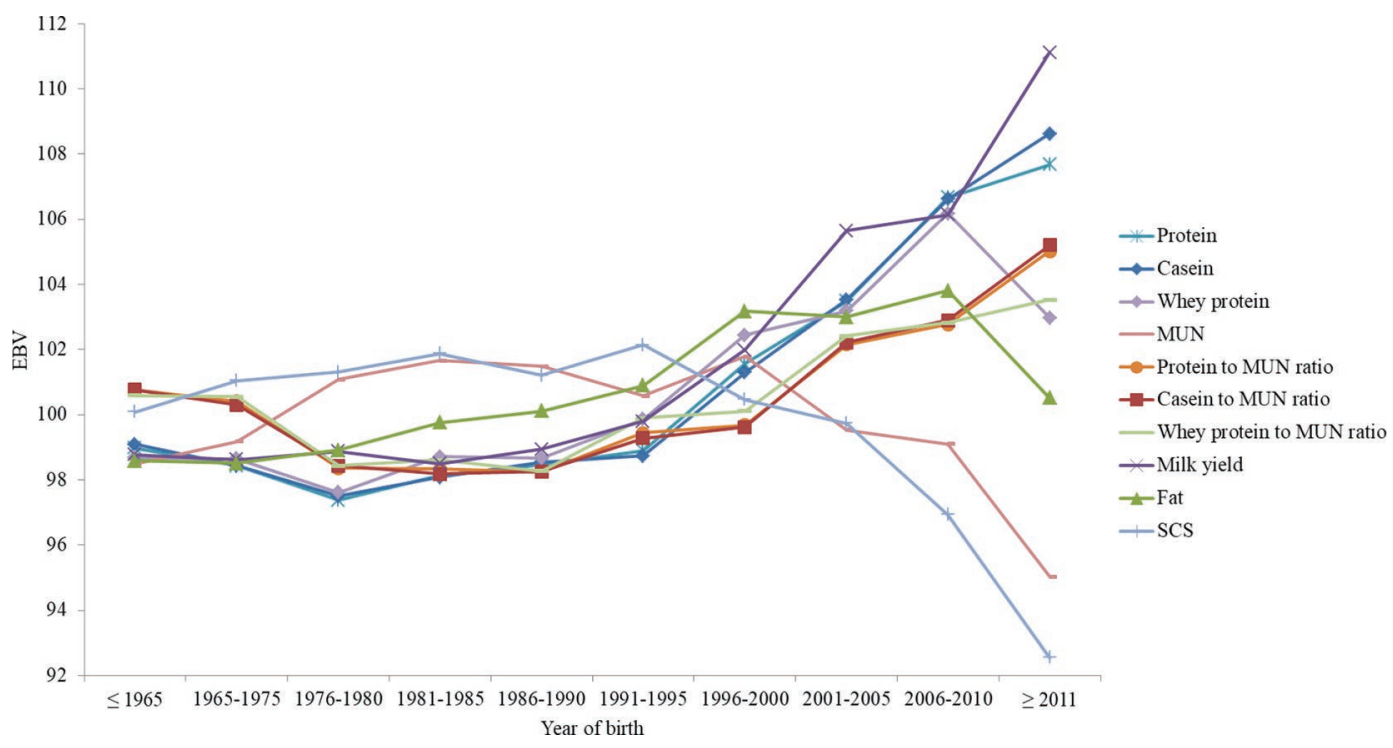

Figure 1. Genetic trend of test-day milk yield, composition, SCS, and nitrogen efficiency indicators by year of birth of Brown Swiss sires $(\mathrm{n}=1,267)$. 
We first assigned an economic value of 1 to milk yield and checked the response to selection of all traits. Our results suggest that if the breeding goal consists solely of milk yield, no response to selection will be observed for the 3 ratios. Nevertheless, some countries (including Italy) place emphasis on protein percentage in their total merit index; therefore, we assigned an economic value of 1 to protein. Selection on solely protein percentage would lead to an indirect positive response to selection of protein-to-MUN ratio. Then, maintaining an economic value of 1 for protein, we tried to assign different economic values to protein-to-MUN ratio or to MUN, to increase the response to selection of proteinto-MUN ratio (our objective). To double the response to selection of protein-to-MUN ratio, a direct emphasis 5 times greater than that given to protein percentage should be placed on the ratio (i.e., economic value $=5$ ), which is hardly feasible in a total merit index. However, the same result can be obtained by giving to MUN one-quarter the emphasis given to protein. Thus, in this last scenario, we assigned an economic value of 1 to protein and -0.25 to MUN. Additionally, placing such emphasis on MUN would lead to an indirect response to selection of casein-to-MUN ratio. Consequently, emphasis should be given to MUN to speed up the process of improving nitrogen utilization efficiency of cows, causing only a negligible reduction in the genetic gain of milk yield and a favorable repercussion in the genetic response on fat and SCS. Moreover, although the variance-covariance matrix previously formed by pooling the bivariate analyses was not positive definite for the 10 traits considered, it was positive definite when considering only 5 traits (milk yield, fat, protein, SCS, and MUN).

In conclusion, our results support that MUN is a useful tool to monitor nitrogen utilization efficiency in dairy cows. Additive genetic variation and heritability exist for MUN and MUN-derived indicators of nitrogen utilization efficiency, suggesting that these traits could be improved through selection. The goal of including, for example, protein-to-MUN ratio in a selection index would be to simultaneously increase the numerator and decrease the denominator, to maximize the improvement of nitrogen utilization efficiency. Our predicted selection response results suggest that this aim can be achieved by directly including protein percentage and MUN in a multitrait selection index. Hence protein-toMUN ratio would not be directly included in the index, but it can be used to evaluate the weight that MUN and protein percentage should receive to obtain the desired result. Thus, the inclusion of MUN in breeding programs has the potential to help achieve the final goal of increasing organic nitrogen such as protein, which is useful for cheese-making, and reducing inorganic nitrogen (MUN) in milk, which is of great importance in countries such as Italy and France with extensive cheese production. Further studies on the relationships with traits such as conformation, fertility, and health are required. Moreover, lactose percentage should also be considered for the definition of possible indicators of nitrogen utilization efficiency.

\section{ACKNOWLEDGMENTS}

This study was supported by "Latteco Project," sottomisura [sub-measure] 10.2 of the National Rural Development Programme (PSRN)-Biodiversity 20142020. The authors thank the Breeders Association of Veneto Region (ARAV, Padova, Italy) for providing test-day data. The authors confirm that they have no conflicts of interest.

\section{REFERENCES}

Aguilar, M., M. D. Hanigan, H. A. Tucker, B. L. Jones, S. K. Garbade, M. L. McGilliard, C. C. Stallings, K. F. Knowlton, and R. E. James. 2012. Cow and herd variation in milk urea nitrogen concentrations in lactating dairy cattle. J. Dairy Sci. 95:7261-7268. https: //doi.org/10.3168/jds.2012-5582.

Ali, A. K. A., and G. E. Shook. 1980. An optimum transformation for somatic cell concentration in milk. J. Dairy Sci. 63:487-490. https: //doi.org/10.3168/jds.S0022-0302(80)82959-6.

Bobbo, T., C. Cipolat-Gotet, G. Bittante, and A. Cecchinato. 2016. The nonlinear effect of somatic cell count on milk composition, coagulation properties, curd firmness modeling, cheese yield, and curd nutrient recovery. J. Dairy Sci. 99:5104-5119. https://doi .org/10.3168/jds.2015-10512.

Broderick, G. A., and M. K. Clayton. 1997. A statistical evaluation of animal and nutritional factors influencing concentrations of milk urea nitrogen. J. Dairy Sci. 80:2964-2971. https://doi.org/10 .3168/jds.S0022-0302(97)76262-3.

Castillo, A. R., E. Kebreab, D. E. Beever, and J. France. 2000. A review of efficiency of nitrogen utilisation in lactating dairy cows and its relationship with environmental pollution. J. Anim. Feed Sci. 9:1-32. https://doi.org/10.22358/jafs/68025/2000.

Groeneveld, E., M. Kovač, and T. Wang. 1990. PEST, a general purpose BLUP package for multivariate prediction and estimation. Pages 488-491 in Proc. 4th World Congress on Genetics Applied to Livestock Production, Edinburgh, UK. http://www.wcgalp.org/ system/files/proceedings/1990/pest-general-purpose-blup-package -multivariate-prediction-and-estimation.pdf.

Jonker, J. S., R. A. Kohn, and R. A. Erdman. 1998. Using milk urea nitrogen to predict nitrogen excretion and utilization efficiency in lactating dairy cows. J. Dairy Sci. 81:2681-2692. https://doi.org/ 10.3168/jds.S0022-0302(98)75825-4.

Jonker, J. S., R. A. Kohn, and R. A. Erdman. 1999. Milk urea nitrogen target concentrations for lactating dairy cows fed according to National Research Council recommendations. J. Dairy Sci. 82:12611273. https://doi.org/10.3168/jds.S0022-0302(99)75349-X.

Miglior, F., A. Fleming, F. Malchiodi, L. F. Brito, P. Martin, and C. F. Baes. 2017. A 100-year review: Identification and genetic selection of economically important traits in dairy cattle. J. Dairy Sci. 100:10251-10271. https://doi.org/10.3168/jds.2017-12968.

Miglior, F., A. Sewalem, J. Jamrozik, J. Bohmanova, D. M. Lefebvre, and R. K. Moore. 2007. Genetic analysis of milk urea nitrogen and lactose and their relationships with other production traits in Canadian Holstein cattle. J. Dairy Sci. 90:2468-2479.

Mitchell, R. G., G. W. Rogers, C. D. Dechow, J. E. Vallimont, J. B. Cooper, U. Sander-Nielsen, and J. S. Clay. 2005. Milk urea ni- 
trogen concentrations: Heritability and genetic correlations with reproductive performance and disease. J. Dairy Sci. 88:4434-4440. https://doi.org/10.3168/jds.S0022-0302(05)73130-1.

Mucha, S., and E. Strandberg. 2011. Genetic analysis of milk urea nitrogen and relationship with yield and fertility across lactation. J. Dairy Sci. 94:5665-5672. https://doi.org/10.3168/jds.2010-3916.

Neumaier, A., and E. Groeneveld. 1998. Restricted maximum likelihood estimation of covariances in sparse linear models. Genet. Sel. Evol. 30:3-26. https://doi.org/10.1186/1297-9686-30-1-3.

Nousiainen, J., K. J. Shingfield, and P. Huhtanen. 2004. Evaluation of milk urea nitrogen as a diagnostic of protein feeding. J. Dairy Sci. 87:386-398. https://doi.org/10.3168/jds.S0022-0302(04)73178-1.

Parker, D. S., M. A. Lomax, C. J. Seal, and J. C. Wilton. 1995. Metabolic implications of ammonia production in the ruminant. Proc. Nutr. Soc. 54:549-563. https://doi.org/10.1079/PNS19950023.

Roy, B., B. Brahma, S. Ghosh, P. K. Pankaj, and G. Mandal. 2011. Evaluation of milk urea concentration as useful indicator for dairy herd management: A review. Asian J. Anim. Vet. Adv. 6:1-19. https://doi.org/10.3923/ajava.2011.1.19.

Rzewuska, K., and T. Strabel. 2013. Genetic parameters for milk urea concentration and milk traits in Polish Holstein-Friesian cows. J. Appl. Genet. 54:473-482. https://doi.org/10.1007/s13353-013 $-0159-8$.

Samoré, A. B., C. Romani, A. Rossoni, E. Frigo, O. Pedron, and A. Bagnato. 2007. Genetic parameters for casein and urea content in the Italian Brown Swiss dairy cattle. Ital. J. Anim. Sci. 6(Suppl. 1):201-203. https://doi.org/10.4081/ijas.2007.1s.201.

Satoła, A., E. Ptak, A. Otwinowska-Mindur, and W. Jagusiak. 2017. Genetic parameters for lactose percentage and urea concentration in milk of Polish Holstein-Friesian cows. Anim. Sci. Pap. Rep. 35:159-172.

Stoop, W. M., H. Bovenhuis, and J. A. M. van Arendonk. 2007. Genetic parameters for milk urea nitrogen in relation to milk production traits. J. Dairy Sci. 90:1981-1986. https://doi.org/10.3168/ jds.2006-434.

Wood, G. M., P. J. Boettcher, J. Jamrozik, G. B. Jansen, and D. F. Kelton. 2003. Estimation of genetic parameters for concentrations of milk urea nitrogen. J. Dairy Sci. 86:2462-2469. https://doi.org/ 10.3168/jds.S0022-0302(03)73840-5.

\section{ORCIDS}

T. Bobbo $\odot$ https://orcid.org/0000-0003-0328-8903

M. Penasa ๑ https://orcid.org/0000-0001-9984-8738

A. Rossoni (i) https://orcid.org/0000-0001-5202-5785

M. Cassandro (ㄱ https://orcid.org/0000-0002-8709-2870 